\title{
Characteristics and Antimicrobial Properties of Active Edible Films Based on Pectin and Nanochitosan
}

\author{
Thi Minh Phuong Ngo ${ }^{1}$, Thanh Hoi Nguyen ${ }^{1}$, Thi Mong Quyen Dang ${ }^{2}$, Thi Xo Tran ${ }^{3}$ and \\ Pornchai Rachtanapun $4,5, *$ (D)
}

1 Department of Chemical Technology and Environment, The University of Danang-University of Technology and Education, Danang 550000, Vietnam; ntmphuong@ute.udn.vn (T.M.P.N.); nthoi@ute.udn.vn (T.H.N.)

2 Department of Postharvest and Food Processing, Faculty of Food Technology, College of Food Industry, Danang 550000, Vietnam; mongquyen76@gmail.com

3 Department of Chemical Engineering, The University of Danang-University of Science and Technology, Danang 550000, Vietnam; tranthixo@gmail.com

4 Division of Packaging Technology, Faculty of Agro-Industry, Chiang Mai University, Chiang Mai 50100, Thailand

5 Cluster of Agro Bio-Circular-Green Industry (Agro BCG), Chiang Mai University, Chiang Mai 50100, Thailand

* Correspondence: pornchai.r@cmu.ac.th; Tel.: +66-635492556

Received: 28 November 2019; Accepted: 12 March 2020; Published: 23 March 2020

\begin{abstract}
This study was aimed at creating new films and determine some functional packaging properties of pectin:nanochitosan films with ratios of pectin:nanochitosan (P:NSC) of 100:0; 75:25; 50:50; $25: 75$ and $0: 100(\% w / w)$. The effects of the proportions of pectin:nanochitosan incorporation on the thickness, mechanical properties, water vapor permeability, water-solubility, and oxygen permeability were investigated. The microstructural studies were done using scanning electron microscopy (SEM). The interactions between pectin and nanochitosan were elucidated by Attenuated total reflectance-Fourier transform infrared (ATR-FTIR). The results showed that the blending of pectin with nanochitosan at proportions of 50:50 increased the tensile strength to $8.96 \mathrm{MPa}$, reduced the water solubility to $37.5 \%$, water vapor permeability to $0.2052 \mathrm{~g} \cdot \mathrm{mm} / \mathrm{m}^{2}$.day. $\mathrm{kPa}$, and the oxygen permeability to $47.67 \mathrm{cc} \cdot \mathrm{mm} / \mathrm{m}^{2}$.day. The results of the contact angle test indicated that P:NCS films were hydrophobic, especially, pectin:nanochitosan films inhibited the growth of Colletotrichum gloeosporioides, Saccharomyces cerevisiae, Aspergillus niger, and Escherichia coli. So, P:NCS films with a proportion of 50:50 can be used as active films to extend the shelf life of food.
\end{abstract}

Keywords: antimicrobial; active packaging; biopolymer; edible film; chitosan; nanochitosan; pectin

\section{Introduction}

Antimicrobial food packaging is a new type of active packaging incorporating natural antimicrobial compounds in order to reduce the food spoilage [1].

Pectin, composed of $\alpha-1,4$-linked galacturonic acid, is a major component of plant cell walls and one of its attractive characteristics is its ability to form good films [2]. However, the pectin films have a poor water vapor barrier and a moderate oxygen barrier, therefore their utilization in food packaging is limited. To solve this problem, films based on pectin and nanochitosan are investigated in this study. Nanochitosan exhibits higher antimicrobial activities and barrier properties than chitosan. Hence, nanochitosan has the potential of becoming a powerful and safe natural antifungal agent which can improve the barrier properties and functionality of films and coatings [3]. 
Therefore, we have developed an inexpensive antimicrobial material which is composed of pectin and nanochitosan. Films formed between pectin chains and nanochitosans are stabilized by hydrogen links and electrostatic interactions [4]. The purpose of the present study was to evaluate some properties of active edible films based on pectin and nanochitosan.

In the present work, we aimed to prepare a pectin:nanochitosan polyelectrolyte complex to develop antimicrobial films. The developed films were characterized by mechanical properties, water vapor permeability, water contact angle, oxygen permeability, Fourier transform infrared (FTIR) spectroscopy and scanning electron microscopy (SEM). In addition, film-forming solutions were tested against four popular kinds of microorganisms which were Escherichia coli, Aspergillus niger, Colletotrichum gloeosporioides, and Saccharomyces cerevisiae.

\section{Results and Discussion}

\subsection{Preparation and Characterization of Nanochitosan}

The nanochitosan was synthesized by the ionic methacrylic acid method according to de Moura [5]. The microstructure of the nanochitosan was studied by SEM at 100,000 $\times$ and 150,000 $\times$ magnification and the acquired micrograph for the nanochitosan film surface is shown in Figure 1. In this work, the particles are nearly spherical and the particle size diameters of the nanochitosan are less than $100 \mathrm{~nm}$.

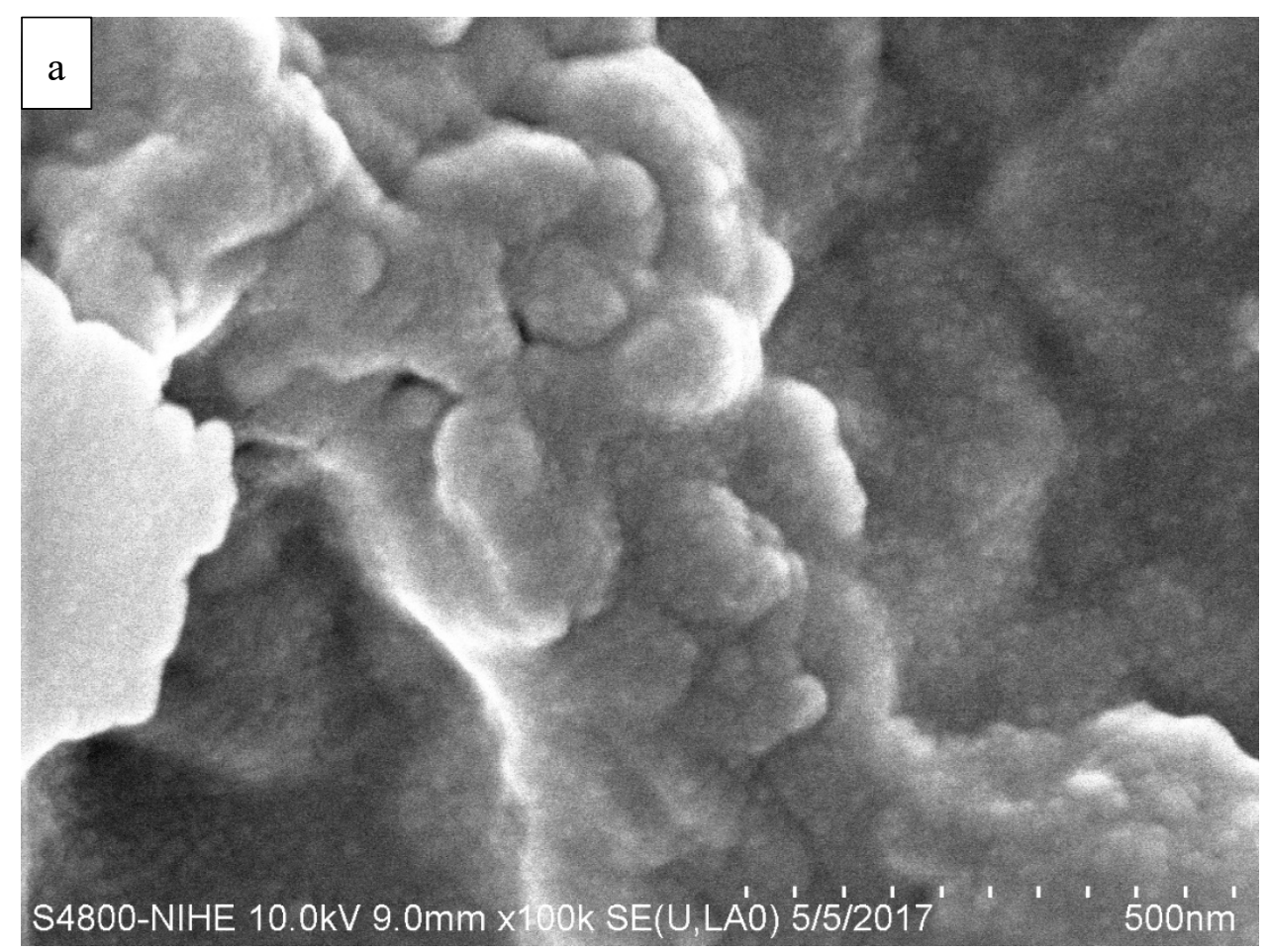

Figure 1. Cont. 


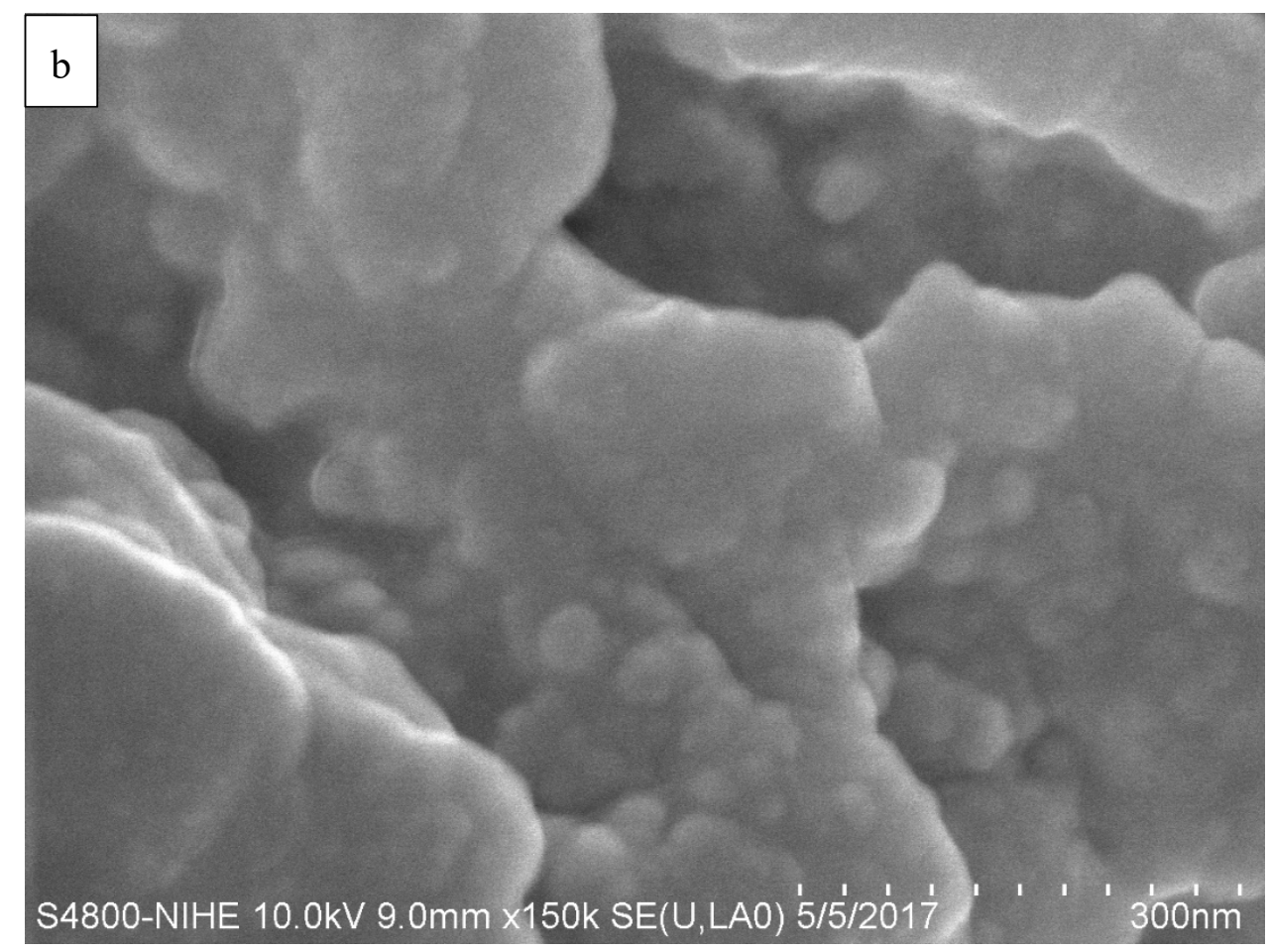

Figure 1. Scanning electron microscopy (SEM) micrograph of nanochitosan film. (a) $100,000 \times$ and (b) 150,000× magnification.

\subsection{Thickness and Mechanical Properties of Films}

Thickness values of the films are shown in Table 1. The pure pectin film was thicker than nanochitosan film solely. Increasing the content of nanochitosan from 25 to $50 \%$ affects the thickness of the composite films. However, on increasing the content of nanochitosan to $75 \%$, the thickness of the nanochitosan film became higher than the pectin films. The decreasing thickness of the films is associated with electronic interaction between the positively charged nanochitosan and negatively charged pectin, caused by decreasing the charged groups of the polymer composite which resulted in a good aggregation between the polymer chains (due to the decrease of electronic repulsion). However, the presence of more nanochitosan caused an increase in the electronic repulsion which resulted in a reduction in the particle aggregation, hence an increased film thickness.

Table 1. Thickness and mechanical properties of films.

\begin{tabular}{cccc}
\hline Films & Thickness, $\mu \mathbf{m}$ & Tensile Strength, MPa & Elongation, $\%$ \\
\hline P:NCS 100:0 & $54.0 \pm 2.50^{\mathrm{b}}$ & $7.10 \pm 0.22^{\mathrm{b}}$ & $7.17 \pm 0.35^{\mathrm{b}}$ \\
P:NCS 75:25 & $46.5 \pm 2.05^{\mathrm{c}}$ & $10.84 \pm 0.38^{\mathrm{a}}$ & $17.22 \pm 0.9^{\mathrm{a}}$ \\
P:NCS 50:50 & $47.7 \pm 1.8^{\mathrm{c}}$ & $8.96 \pm 0.19^{\mathrm{b}}$ & $10.60 \pm 0.29^{\mathrm{b}}$ \\
P:NCS 25:75 & $61.2 \pm 2.46^{\mathrm{a}}$ & $2.86 \pm 0.09^{\mathrm{c}}$ & $8.65 \pm 0.42^{\mathrm{b}}$ \\
P:NCS 0:100 & $43.0 \pm 1.46^{\mathrm{c}}$ & $3.57 \pm 0.15^{\mathrm{c}}$ & $10.52 \pm 0.43^{\mathrm{b}}$ \\
\hline
\end{tabular}

Note: Alphabets (a,b and $c)$ in a column represent significant differences $(p \leq 0.05)$. 
Mechanical properties (tensile strength (TS) and elongation (E)) of all the films are presented in Table 1. The tensile strength of the pectin films was $7.10 \pm 0.22 \mathrm{MPa}$ and increased to a maximum value of $10.84 \pm 0.38 \mathrm{MPa}$ when the nanochitosan concentration increased by $25 \%$. However, further increases in the nanochitosan concentration (50 and 75\%) decreased the TS of the films.

The enhanced TS and E values of P:NCS 75:25 and P:NCS 50:50 films can be explained by the higher number of interactions between the carboxylic groups of pectin and amine groups of nanochitosan. The influence of nanoparticles on the mechanical properties of films was investigated by Chang et al. and Parris et al. [6,7]. When nanochitosan particles were dispersed in the pectin matrix, the strong interaction between the nanoparticles and pectin may reduce the mobility and improve the tensile strength. Similarly, the results indicated that the P:NCS films presented a better elongation compared to the pectin films and nanochitosan films. In the pure pectin matrices and nanochitosan matrices, links are formed by hydrogen bonds and Van der Waals interactions. These weak interactions result in little flexibility and a brittle film. At nanochitosan concentration of $75 \%$, the films became rougher and thicker and the interaction between pectin and nanochitosan is poor. As discussed above, adding nanochitosan at concentrations of 25 and 50\% may improve the mechanical properties.

\subsection{Contact Angle ( $C A)$ of the Films}

The contact angles of the films are shown in Table 2.

Hydrophilicity can be investigated by the water contact angle of the film. The lower the contact angle, the more hydrophilic the film is [8]. As can be seen from Table 2, the initial contact angles of the pectin films and the nanochitosan films were $62.1^{\circ}$ and $84.8^{\circ}$, respectively. These results suggest that the nanochitosan film was more hydrophobic than the pectin film. The addition of nanochitosan to the pectin films led to an improvement in the hydrophobicity of the film surface. As the ratio of nanochitosan increased from 25 to $75 \%$, the contact angle increased from $89.3^{\circ}$ to $97.1^{\circ}$ for the P:NCS 75:25 and P:NCS 25:75 films, respectively, but there was no significant difference between the CA of the P:NCS 75:25 films and P:NCS 50:50 films.

The increase in CA of P:NCS films may be attributed to the ionic interactions formed between the nanochitosan and the pectin, reducing the hydrophilic groups. The higher the amount the hydrophobic acetyl groups in the nanochitosan, the higher the contact angle was. Moreover, the contact angle is also related to the roughness of the film surface. 
Table 2. The contact angle of films.

\begin{tabular}{|c|c|c|c|c|}
\hline \multirow{2}{*}{ Films } & \multicolumn{2}{|c|}{ Contact angle, $^{\circ}$} & \multicolumn{2}{|c|}{ Image } \\
\hline & Initial CA & After $12 \mathrm{~s}$ & Initial CA & After $12 \mathrm{~s}$ \\
\hline P:NCS100:0 & $62.1 \pm 2.12^{c}$ & $45.20 \pm 2.96^{\mathrm{d}}$ & & \\
\hline P:NCS 75:25 & $89.3 \pm 6.86^{a b}$ & $82.60 \pm 6.85^{b}$ & & \\
\hline P:NCS 50:50 & $95.4 \pm 10.74^{a b}$ & $86.23 \pm 3.01 \mathrm{ab}$ & & \\
\hline P:NCS 25:75 & $97.1 \pm 2.9^{a}$ & $92.5 \pm 3.8^{a}$ & & \\
\hline P:NCS0:100 & $84.80 \pm 1.75^{b}$ & $73.37 \pm 1.90^{c}$ & & \\
\hline
\end{tabular}

Note: Alphabets (a, b, $\mathrm{c}$ and $\mathrm{d})$ in a column represent significant differences $(p \leq 0.05)$.

\subsection{Hydration Properties of the Films}

Table 3 shows the solubility, swelling degree (SD), water vapor permeability (WVP), and water vapor transmission rate (WVTR) of the films. Pectin films exhibited high solubility when compared with the other films. Comparison of these values for films of different ratios of pectin and nanochitosan revealed a decrease in the solubility of P:NCS films when the proportion of nanochitosan was increased from 25 to $75 \%$. The reduction of water solubility is a combined result of the optimum association between the $\mathrm{NH}_{3}{ }^{+}$groups of nanochitosan and the $\mathrm{COO}^{-}$groups of pectin. 
Table 3. Hydration properties of the films.

\begin{tabular}{ccccc}
\hline Films & $\begin{array}{c}\text { Solubility, } \\
\mathbf{\%}\end{array}$ & $\begin{array}{c}\text { SD, } \mathbf{5 0 ~} \mathbf{m} \\
\mathbf{\%}\end{array}$ & $\begin{array}{c}\mathbf{W V P}, \\
\mathbf{g} \cdot \mathbf{m m} / \mathbf{m}^{\mathbf{2}} \cdot \mathbf{d a y} \cdot \mathbf{k P a}\end{array}$ & $\begin{array}{c}\mathbf{W V T R} \\
\mathbf{g} / \mathbf{m}^{\mathbf{2}} \cdot \mathbf{d}\end{array}$ \\
\hline P: $100: 0$ & $100 \pm 0^{\mathrm{a}}$ & $-100 \pm 0^{\mathrm{d}}$ & $1.33 \pm 0.0285^{\mathrm{a}}$ & $38.77 \pm 0.83^{\mathrm{a}}$ \\
P:NCS 75:25 & $45.65 \pm 1.69^{\mathrm{b}}$ & $249.45 \pm 12.73^{\mathrm{b}}$ & $0.2699 \pm 0.0089^{\mathrm{c}}$ & $9.91 \pm 0.33^{\mathrm{c}}$ \\
P:NCS 50:50 & $37.5 \pm 1.69^{\mathrm{c}}$ & $117.8 \pm 8.77^{\mathrm{c}}$ & $0.2052 \pm 0.0083^{\mathrm{d}}$ & $8.10 \pm 0.33^{\mathrm{d}}$ \\
P:NCS 25:75 & $11.11 \pm 1.13^{\mathrm{d}}$ & $230.98 \pm 11.38^{\mathrm{b}}$ & $0.5922 \pm 0.0204^{\mathrm{b}}$ & $17.26 \pm 0.60^{\mathrm{b}}$ \\
P:NCS 0:100 & $37.84 \pm 1.98^{\mathrm{c}}$ & $443.15 \pm 21.28^{\mathrm{a}}$ & $0.1755 \pm 0.0085^{\mathrm{d}}$ & $9.24 \pm 0.45^{\mathrm{cd}}$ \\
\hline
\end{tabular}

Note: Alphabets (a, b, c and d) in a column represent significant differences $(p \leq 0.05)$.

Pectin, with a $43.48 \%$ degree of esterification (DE), contains a large number of carboxylic groups. The $\mathrm{pKa}$ of pectin and nanochitosan was found to be at $\mathrm{pH} 3.5$ and 7.66, respectively. The $\mathrm{pH}$ of the solution in this study was 4.5 , so the pectin chains were completely anionic and nanochitosan chains were fully protonated with free amino groups. The higher the number of cations in the nanochitosan, the better the electrostatic repulsion between their chains, leading to a higher swelling degree due to the solvation with more water molecules [4]. Similarly, the higher the anion content in the pectin, the higher the swelling degree of the pectin film is. As discussed above, the lowest SD of P:NCS 50:50 film can be explained in that ionic links were formed by the $\mathrm{NH}_{3}{ }^{+}$groups of the nanochitosan and the $\mathrm{COO}^{-}$groups of the pectin, therefore reducing the electrostatic repulsion between the chains.

When nanochitosan content was increased from 25 to $50 \%$ in the composite films, WVTR and WVP were decreased because the nanochitosan could be easily dispersed into the porous films. As a result, the more compact structure of the film formed more tortuous pathways for diffusion of water molecules and therefore, decreased the WVP and WVTR of the films. On the other hand, when nanochitosan was added into the pectin matrix, this reduced the number of carboxyl groups which decreased the WVTR and WVP values. At the nanochitosan concentration of 75\%, the WVP and WVTR values increased because the surface of films became rougher and thicker due to the high concentration of nanochitosan, and there were more numerous and larger holes in the film matrices.

\subsection{Moisture Sorption Isotherm of the Films}

Figure 2 shows the moisture sorption isotherms of the P:NCS films with various contents. The moisture absorption isotherm graphs of the P:NCS films with different contents have a characteristic type II sigmoidal shape.

Pectin films can have an uptake of up to $61.8 \%$ moisture when conditioned at $93 \% \mathrm{RH}$ and $25^{\circ} \mathrm{C}$. Nanochitosan films, and all the P:NCS films with various ratios, have a moisture uptake of about $<34.3 \%$ at $93 \% \mathrm{RH}$ and $25^{\circ} \mathrm{C}$, a lower moisture uptake compared with the pectin films.

At each relative humidity, the equilibrium moisture content (EMC) of the P:NCS films decreased with increasing NCS concentrations, from 0 to $100 \%$, with the maximum EMC obtained in a P and P:NCS 75:25 film. The P and P:NCS 75:25 films were more hydrophilic, therefore, they could absorb more moisture. There was a decrease in EMC value when increasing the nanochitosan concentration. It was noted that the film samples had water droplets on the surface at $99 \% \mathrm{RH}$ and the EMC of films was over $200 \%$. Therefore, these data points were omitted. 


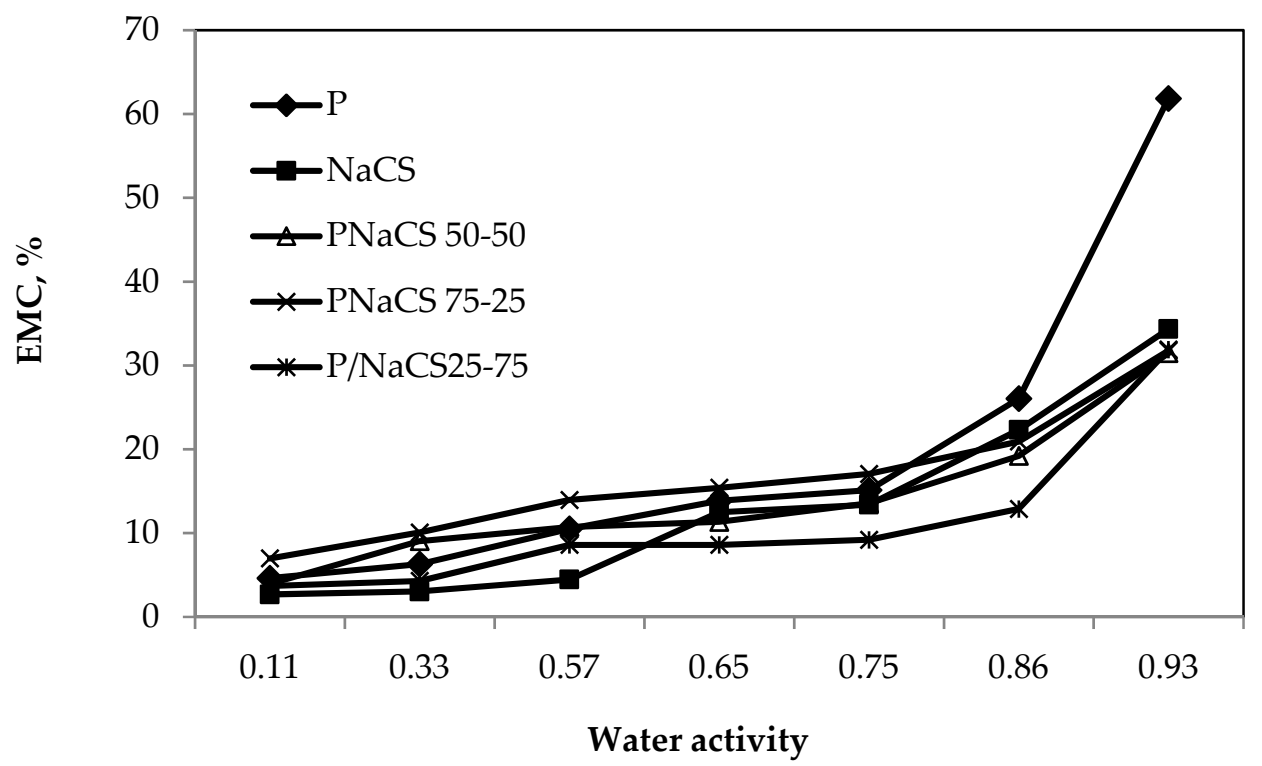

Figure 2. Moisture sorption isotherms of P:NCS films at $25 \pm 0.5^{\circ} \mathrm{C}$.

\subsection{Color and Transparency of the Films}

The color of films may affect the consumers' acceptability of the products. The results of color assessments for the films are presented in Table 4 . The $\mathrm{a}^{*}$ value shows the color of the film changed from green to red as the $a^{*}$ value increased from a negative value to a positive value. An increase in the $\mathrm{b}^{*}$ value indicated that the color of the film was becoming more yellow. The $\mathrm{L}^{*}$ parameter was used to describe the contrast between dark and light with the range from 0 to 100 . The chroma value shows the intensity of the color which changed from neutral to dull, and then to intense when the chroma increased from 0 to 50 and 100, respectively. The hue value shows the change of color from red-yellow to yellow, and then a yellowish-green color when the hue values increased from $49^{\circ}$ to $90^{\circ}$, and $135^{\circ}$, respectively.

Table 4 shows the color values of the films at different ratios. Because NCS had a yellow color and the pectin film had a very slight yellow color, increasing the nanochitosan content significantly affected $(p=0.05)$ the $\mathrm{a}^{*}$ and $\mathrm{b}^{*}$ values of the film surface. Increasing the concentration of nanochitosan from 25 to $100 \%$ slightly increased the greenness $a^{*}$ values from -0.23 to 0.22 . The color of the films changed to yellowish as indicated by an increase of the $b^{*}$ value from 2.57 for pectin films to 9.27 for the nanochitosan films, but the $\mathrm{L}^{*}$ value of the P films and P:NCS films, with various proportions, were not significantly different.

Table 4. Color of films.

\begin{tabular}{cccccc}
\hline \multirow{2}{*}{ Films } & \multicolumn{5}{c}{ Parameters } \\
\cline { 2 - 6 } & $\mathbf{L}^{*}$ & $\mathbf{a}^{*}$ & $\mathbf{b}^{*}$ & Chroma & Hue \\
\hline P:NCS 100:0 & $96.24 \pm 0.31^{\mathrm{a}}$ & $0.14 \pm 0.01^{\mathrm{b}}$ & $2.57 \pm 0.12^{\mathrm{d}}$ & $2.57 \pm 0.11^{\mathrm{d}}$ & $86.81 \pm 0.5^{\mathrm{b}}$ \\
P:NCS 75:25 & $95.76 \pm 0.2^{\mathrm{a}}$ & $-0.23 \pm 0.01^{\mathrm{d}}$ & $5.98 \pm 0.31^{\mathrm{c}}$ & $5.99 \pm 0.25^{\mathrm{c}}$ & $87.09 \pm 0.73^{\mathrm{b}}$ \\
P:NCS 50:50 & $95.69 \pm 0.31^{\mathrm{a}}$ & $-0.13 \pm 0.02^{\mathrm{c}}$ & $6.59 \pm 0.63^{\mathrm{c}}$ & $6.60 \pm 0.63^{\mathrm{c}}$ & $88.12^{\mathrm{a}} \pm 0.11^{\mathrm{ab}}$ \\
P:NCS 25:75 & $95.48 \pm 0.25^{\mathrm{a}}$ & $0.10 \pm 0.01^{\mathrm{b}}$ & $7.49 \pm 0.32^{\mathrm{b}}$ & $7.49 \pm 0.32^{\mathrm{b}}$ & $89.25 \pm 0.26^{\mathrm{a}}$ \\
P:NCS 0:100 & $94.51 \pm 0.18^{\mathrm{b}}$ & $0.22 \pm 0.01^{\mathrm{a}}$ & $9.27 \pm 0.43^{\mathrm{a}}$ & $9.28 \pm 0.42^{\mathrm{a}}$ & $88.62 \pm 0.35^{\mathrm{a}}$ \\
\hline
\end{tabular}

Note: Alphabets (a, b, $\mathrm{c}$ and $\mathrm{d})$ in a column represent significant differences $(p \leq 0.05)$. 


\subsection{Antimicrobial Action of Film-Forming Solutions}

The antimicrobial action of the P:NCS solutions were tested against E. coli, S. cerevisiae, A. niger, and C. gloeosporioides. The inhibition zone diameter of the film-forming solutions against the growth of selected microorganisms is given in Figure 3. The antimicrobial activities of the P:NCS film-forming solution samples are predicted from the inhibition zone diameter measured in $\mathrm{mm}$.

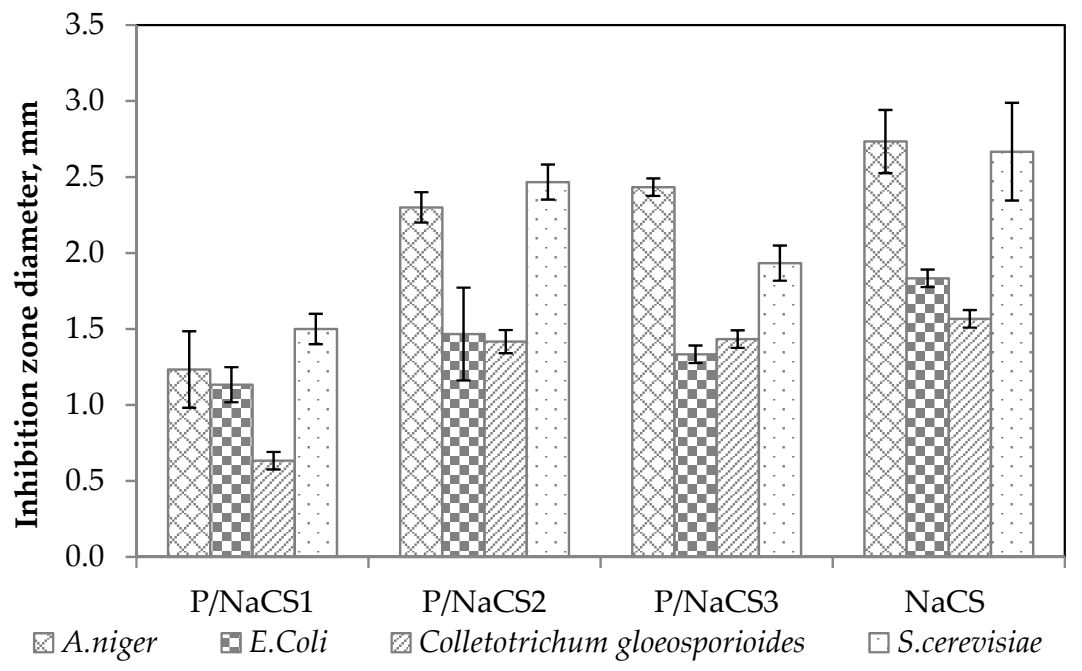

Figure 3. Antimicrobial activities of all films.

From the observed zone of inhibition values of all films presented in Figure 3, it was identified that film-forming solutions with nanochitosan had antibacterial activity towards four strains of microorganisms: E. coli, S. cerevisiae, A. niger and C. gloeosporioides. However, the pectin film did not have any inhibitory effect against the four tested microorganisms. Antimicrobial activity varied according to microorganism strains. These suspensions have been observed to act better on Aspergillus niger and Saccharomyces cerevisiae than on Escherichia coli and Colletotrichum gloeosporioides. The antimicrobial activity of NCS depends on its correlation with the physical characteristics of the nanoparticle size and surface charge of the microorganisms. These results demonstrate that nanochitosan exhibited antimicrobial activity due to the special characteristics of the nanoparticles such as small and compact particles, as well as high surface charge. The antimicrobial property of the film-forming solutions was improved with the increase in the concentration of NCS from 25 to $50 \%$. The mechanism of antimicrobial activity of nanochitosan is proposed by two theories: First, nanochitosan with $\mathrm{NH}_{3}{ }^{+}$groups will interact with the negatively charged surface of the microbial cell membrane so as to disrupt the functions of the cell membrane by breaking some components or by inhibiting the activity of cells, as a result, killing the microbial cells. Second, nanochitosan might be able to penetrate through the microbial cell membrane and bind to its DNA and as a result, prohibit the synthesis of the RNA, enzymes, and protein [9]. The reason for the reduced inhibition capacity of P:NCS 25:75 film compared with P:NCS 50:50 film could be caused by the aggregation and unequal dispersion of nanochitosan which decreased the contact between NCS and the microbial surface [10]. Antimicrobial activity of all the films also depends on the type of microorganism because of the different cellular structures and compositions of microorganisms, due to the mechanism of interaction between the $-\mathrm{NH}_{3}+$ groups of nanochitosan and the microbial structure. Importantly, chitosan nanoparticles exhibit potent bactericidal activity but do not show cytotoxicity on mammalian cells, according to Verma [11].

\subsection{Oxygen Barrier Property of the Films}

Oxygen is an important factor that causes oxidation which initiates several food changes which affects the shelf life of fruits [12]. The oxygen permeability (OP) and oxygen transmission rate (OTR) of all the films are presented in Table 5. 
After investigating the solubility, WVP, WVTR, and antimicrobial activity of all the films, the P:NCS 50:50 film was found to be more suitable for application in food preservation than the P:NCS 75:25 film and the P:NCS 25:75 film. Hence, the P:NCS 50:50 film was selected for further investigation. OP and OTR of the films are shown in Table 5. The OTR of the P and NCS films were 671.0125 and 320.8 $\mathrm{cc} / \mathrm{m}^{2} \cdot \mathrm{d}$, and the OP of P and NCS films were 1320.89 and $832.23 \mathrm{cc} \cdot \mathrm{mm} / \mathrm{m}^{2} \cdot \mathrm{d}$, indicating that these films were good oxygen barriers compared with low-density polyethylene and high-density polyethylene, with OTR values of 7000-8500, and $2300-3100 \mathrm{cc} / \mathrm{m}^{2}$.day, respectively. Generally, hydrophilic films show good oxygen barrier properties. A combination of pectin and nanochitosan helped decrease the OP of P:NCS 50:50 films. The improvement of the O2 barrier properties of the P:NCS 50:50 films was probably due to the formation of intermolecular hydrogen bonds between pectin chains NCS and hydrogen bonds between pectin and NCS, and the interaction of $-\mathrm{NH}_{3}{ }^{+}$groups of $\mathrm{NCS}$ and $-\mathrm{COO}^{-}$ groups of pectin. The increased interaction resulted in a compact film with a low OP.

Table 5. Oxygen permeability (OP) and oxygen transmission rate (OTR).

\begin{tabular}{ccc}
\hline Films & $\begin{array}{c}\text { OP, } \\
\mathbf{c c} \cdot \mathbf{m m} / \mathbf{m}^{\mathbf{2}} \cdot \mathbf{d}\end{array}$ & $\begin{array}{c}\text { OTR, } \\
\mathbf{c c} / \mathbf{m}^{2} \cdot \mathbf{d}\end{array}$ \\
\hline P:NCS 100:0 & $1320.89 \pm 88.29^{\mathrm{a}}$ & $671.01 \pm 47.11^{\mathrm{a}}$ \\
P:NCS 75:25 & $836.89 \pm 56.12^{\mathrm{c}}$ & $350.54 \pm 18.99^{\mathrm{bc}}$ \\
P:NCS 50:50 & $47.67 \pm 5.11^{\mathrm{d}}$ & $18.63 \pm 2.17^{\mathrm{d}}$ \\
P:NCS 25:75 & $898.75 \pm 61.44^{\mathrm{b}}$ & $409.03 \pm 35.63^{\mathrm{b}}$ \\
P:NCS 0:100 & $832.23 \pm 49.89^{\mathrm{c}}$ & $320.8 \pm 25.88^{\mathrm{c}}$
\end{tabular}

Note: Alphabets (a,b and c) in a column represent significant differences $(p \leq 0.05)$.

\subsection{Fourier Transform Infrared (FTIR) Analysis of Pectin, Pectin:Nanochitosan and Nanochitosan Films}

Figure 4 shows the spectra of the pectin films, the nanochitosan films, and the pectin-nanochitosan films. It is known that the peaks of the chitosan were related to the $\mathrm{C}=\mathrm{O}$ stretching bands of amide I at $1635 \mathrm{~cm}^{-1}$ and to amide II at $1539 \mathrm{~cm}^{-1}$ [13]. These peaks slightly shifted to $1590 \mathrm{~cm}^{-1}$ in the nanochitosan. The absorption peak at $1590 \mathrm{~cm}^{-1}$ could be related to the bond formed between the $\mathrm{NH}^{2}$ groups of chitosan and methacrylic acid.

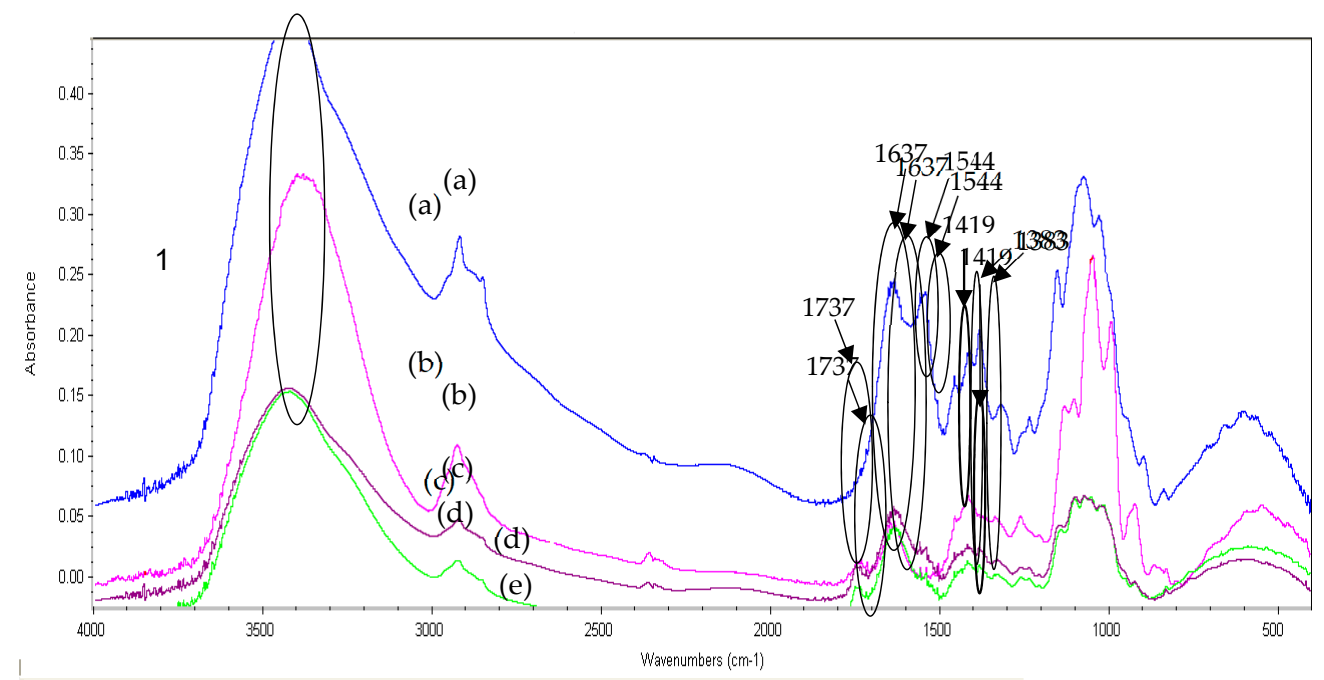

Figure 4. Fourier transform infrared (FTIR) spectra of nanochitosan film (a), P:NCS 50:50 film (b), P:NCS 75:25 film (c) and pectin film (d).

The peak of pectin is related to the $\mathrm{C}=\mathrm{O}$ stretching in the ester form at $1737 \mathrm{~cm}^{-1}$, the $\mathrm{C}=\mathrm{O}$ stretching at $1637 \mathrm{~cm}^{-1}$, and the $\mathrm{COO}^{-}$symmetric stretching at $1417 \mathrm{~cm}^{-1}$ [14]. The peak of nanochitosan is related to the N-H of amide I stretching at $1630 \mathrm{~cm}^{-1}, \mathrm{~N}-\mathrm{H}$ of amide II stretching at $1544 \mathrm{~cm}^{-1}$, and $-\mathrm{NH}_{3}{ }^{+}$symmetric stretching at $1383 \mathrm{~cm}^{-1}$. 
For the spectra of P:NCS films, the main changes were in the range of $1500-1700 \mathrm{~cm}^{-1}$ corresponding to the interaction of amine groups on nanochitosan and the carboxylic groups of pectin. After reacting, the vibrational band corresponding to the primary amino groups at $1544 \mathrm{~cm}^{-1}$ disappeared while bands at 1419 and $1383 \mathrm{~cm}^{-1}$ were formed, indicating that there are interactions between pectin and nanochitosan. The increase in tensile strength values (Table 1) upon NCS addition illustrates pectin and nanochitosan interactions. NaCS addition decreases the number of $\mathrm{OH}$ groups in the pectin matrix. As a result, nanochitosan interactions may reduce the length of the pathway for water and gas migration, which may be due to the decreased permeance. These results confirmed that a reaction had occurred between pectin and NCS.

\subsection{Scanning Electron Microscopy (SEM)}

The SEM images of the surface and cross-section of P, P:NCS 75:25, P:NCS 50:50, P:NCS 25:75, and NCS films are shown in Figure 5.

The pectin film presented a smooth and uniform structure with only a few small solid particles on the surface. The nanochitosan films had rougher surfaces and contained some holes, as seen throughout the images of the surface and cross-section. These holes were probably the result of defects formed in the films caused by the repulsion force of positively charged groups in the nanochitosan. The surface of P:NCS 50:50 film was smoother than NCS film's, which indicates good compatibility between pectin and nanochitosan. The microstructure of the P:NCS film presents small pores across the surface, thus showing the low water vapor permeability, oxygen permeability, and high tensile strength. Moreover, interactions between NCS and P made the surface of the films more hydrophobic, which relates to a lower WVP and water solubility.
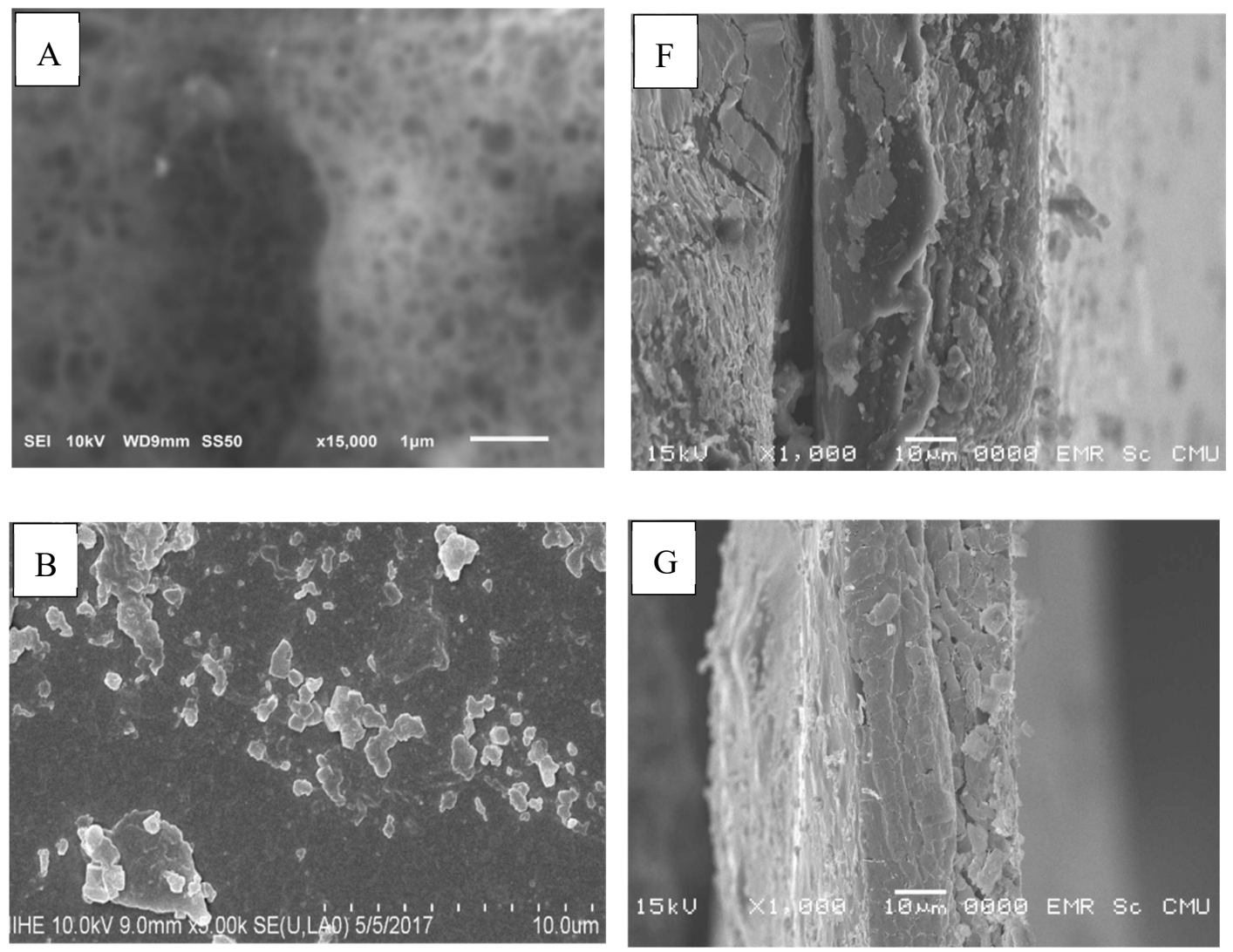

Figure 5. Cont. 

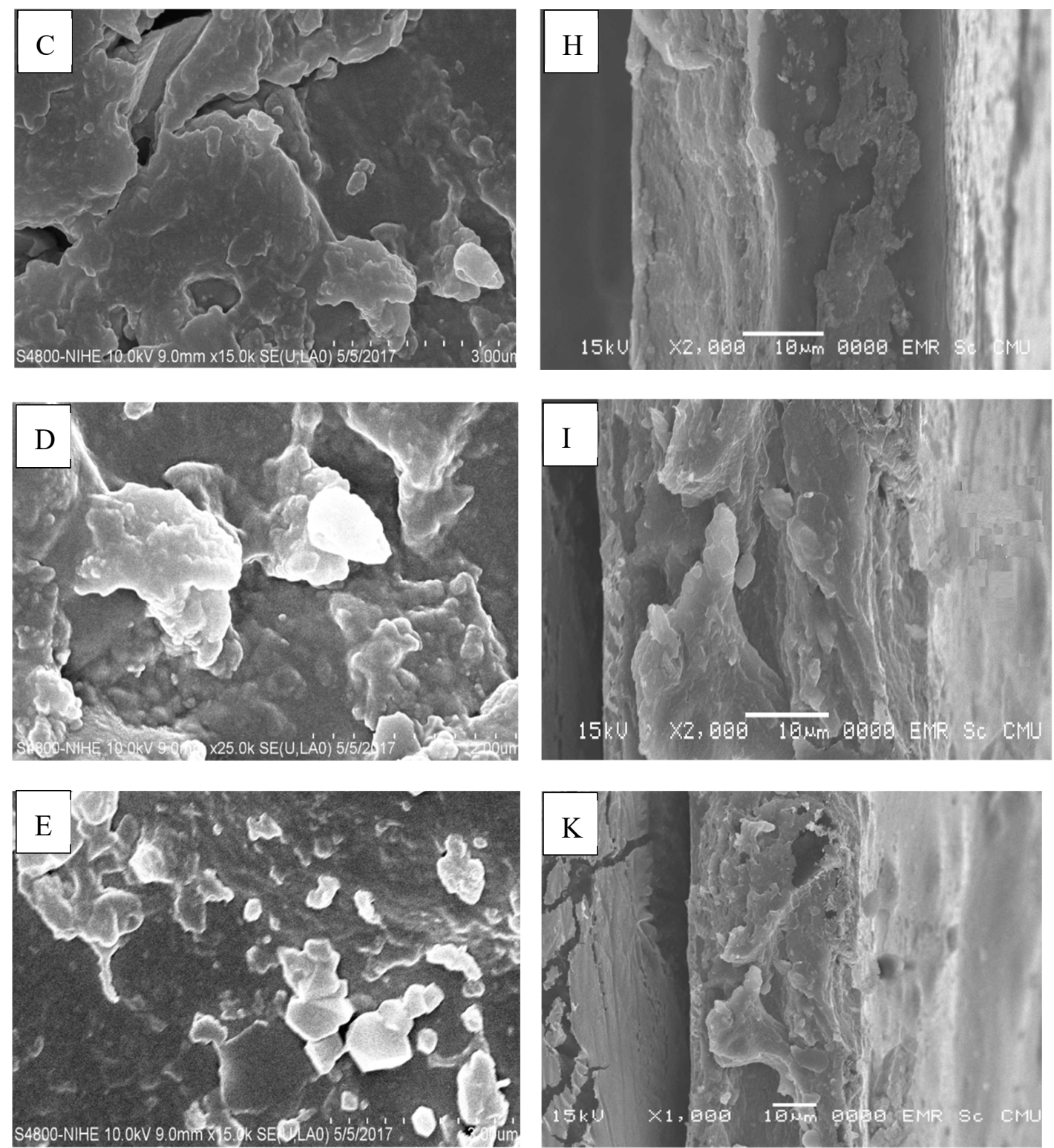

Figure 5. SEM images of surface of P, P:NCS 75:25, P:NCS 50:50, P:NCS 25:75, NCS films (A-E, respectively) and SEM images of cross-section of P, P:NCS 75:25, P:NCS 50:50, P:NCS 25:75, NCS films (F-K, respectively).

\section{Materials and Methods}

\subsection{Materials}

Chitosan (CS) (MW = $70 \mathrm{kDa}$, degree of deacetylation of 90\%) was purchased from Vietnamese Chitosan Co., Ltd. Methacrylic acid (MAA), potassium persulfate $\left(\mathrm{K}_{2} \mathrm{~S}_{2} \mathrm{O}_{8}\right)$, and acetic acid (CH3COOH) were purchased from Merck, Germany. Glycerol and $\mathrm{CaCl} 2$ were purchased from Xilong, China and BHI medium was purchased from Sigma-Aldrich, Saint Louis, MO, USA.

The pectin $(\mathrm{P})$ was extracted from Tiliacora triandra using a heating method [15]. The degree of esterification of pectin was 48.36 and its molecular weight was $111.1 \mathrm{kDa}$.

Nanochitosan (NCS) were prepared by polymerizing methacrylic acid (MAA) in chitosan (CS) solution according to the method described by Nguyet and de Moura $[5,16,17]$. Firstly, chitosan was dissolved in a $0.5 \%$ MMA solution for $12 \mathrm{~h}$. The chitosan concentration used in the synthesis was $0.8 w / w \% . \mathrm{K}_{2} \mathrm{~S}_{2} \mathrm{O}_{8}$, with a concentration of $0.6 \mathrm{mmol}$ was then added to the chitosan-methacrylic 
solution at $70^{\circ} \mathrm{C}$ for $1 \mathrm{~h}$ under stirring. After that, the mixture was cooled at $4{ }^{\circ} \mathrm{C}$. The suspension was centrifuged at $4000 \mathrm{r} / \mathrm{min}$ for $30 \mathrm{~min}$ and a suspension was obtained [5]. Chitosan nanoparticles were twice washed in distilled water, producing a chitosan nanoparticles suspension (NCS).

\subsection{Film Preparation}

The pectin:nanochitosan films were prepared as follows: $2 \mathrm{~g}$ pectin was dissolved in $98 \mathrm{~g}$ distilled water and homogenized at $60{ }^{\circ} \mathrm{C}$. Glycerol was used as a plasticizer at $50 \%(\% w / w$ of polymer). After complete dissolution, the $\mathrm{pH}$ was adjusted to 4.5 measured by a $\mathrm{pH}$ meter. Then, $2 \%$ nanochitosan suspension was added slowly into the pectin solution. The mixture was vigorously stirred for an hour at room temperature. The mixture was stored at $4{ }^{\circ} \mathrm{C}$ without mixing for a day to remove air bubbles. The final solution was poured onto a series of molds (size $15 \mathrm{~cm} \times 15 \mathrm{~cm}$ ). Films were dried, peeled off, and conditioned at $53 \pm 1 \% \mathrm{RH}$, and $25 \pm 1^{\circ} \mathrm{C}$ for 5 days before testing.

Five films were prepared with the ratios of pectin:nanochitosan (P:NCS) as follows: 100:0, 75:25, 50:50, 25:75 and 0:100.

\subsection{Film Thickness}

Film thickness was determined by a thickness gauge (Model PCM 137, No.2046S, Tokyo, Japan) with $0.01 \mathrm{~mm}$ accuracy. Ten random positions on the film sample were used to measure the thickness. The measurements were repeated in triplicate.

\subsection{Film Solubility}

The water solubility of the film was measured as the percentage of dry matter of the film solubilized in water after $24 \mathrm{~h}$ according to Gontard, et al. [18]. Tests were performed in triplicate.

\subsection{Swelling Degree (SD)}

Films with a dimension of $25 \mathrm{~mm} \times 25 \mathrm{~mm}$ were weighed and immersed in distilled water at $25^{\circ} \mathrm{C}$ for $50 \mathrm{~min}$. Water was then removed from the films by placing on dry filter papers and the films were re-weighed. Tests were repeated in triplicate [19]. The swelling degree was determined using Equation (1):

$$
S D=\frac{m_{f-} m_{i}}{m_{i}} \times 100, \%
$$

Where $m_{f}$ and $m_{i}$ are the weights of the swollen and initial samples, respectively.

\subsection{Water Vapor Permeability (WVP) and Water Vapor Transmission rate (WVTR)}

The WVP of the films was measured gravimetrically at $25^{\circ} \mathrm{C}\left( \pm 1^{\circ} \mathrm{C}\right)$ according to ASTM method E96 (2000). The preparation process was described in detail by Rachtanapun [20]. Tests were performed in triplicate. The WVP was calculated using Equation (2):

$$
M V P=\frac{w \cdot x}{t \cdot A \cdot P_{0} \cdot\left(R H_{1}-R H_{2}\right)}
$$

Where: $w / t$ is the constant rate of weight change when a straight line adequately fits the weight change versus time plot by linear regression with $R^{2}>0.99, x$ is the thickness of film $(\mathrm{mm}), A$ is the test area $\left(23.76 \mathrm{~cm}^{2}\right), P_{o}$ is the partial pressure of the water vapor at $25^{\circ} \mathrm{C}(3.159 \mathrm{kPa})$, and $\left(R H_{1}-R H_{2}\right)$ is the relative humidity difference between the two sides of the film [21].

The WVTR of the films was calculated from the slope of the straight line $(\mathrm{g} / \mathrm{day})$ divided by the transfer area $\left(\mathrm{m}^{2}\right)$. 


\subsection{Moisture Sorption Isotherm}

Moisture sorption was determined according to the method reported by Ngo et al. [21]. The equilibrium moisture content $(E M C)$ ( $\mathrm{g}$ water/100 $\mathrm{g}$ dry solid) of the samples at each water activity was determined using Equation (3) [22]:

$$
E M C=\frac{W_{e}}{W_{i}}\left(M_{i}+1\right)-1
$$

Where EMC is the equilibrium moisture content (g water $/ 100 \mathrm{~g}$ dry solid), $W_{e}$ is the equilibrium weight of the film (g), $W_{i}$ is the initial weight of the film $(\mathrm{g})$, and $M_{i}$ is the initial moisture content of the film $(\mathrm{g} / \mathrm{g})[21]$. Tests were performed in triplicate.

\subsection{Mechanical Properties}

Mechanical properties were directly measured via the tensile properties and \% elongation of the films by a Universal Testing Machine H1KS using the ASTM D882-10 method [8]. The films were cut into rectangles of $150 \mathrm{~mm} \times 25 \mathrm{~mm}$. The initial grip separation was $125 \mathrm{~mm}$ and the rate of grip separation was $12.5 \mathrm{~mm} / \mathrm{min}$. The parameters determined were maximum load at break (MPa), and extension of length at rupture (\%). The tensile strength (TS) and percentage of elongation (\%E) for each film were calculated using the following Equations (4) and (5) [23]:

$$
\begin{gathered}
\text { TS }=\frac{\text { Maximum load at break }}{\text { Transverse section area }}, N \\
\% E=\frac{\text { Extension of length at rupture }}{\text { Initial length }} \times 100, \%
\end{gathered}
$$

\subsection{Color Measurement}

Color ( $\mathrm{L}^{*}, \mathrm{a}^{*}, \mathrm{~b}^{*}$, chroma, and hue) of films were measured using the Hunter lab color meter Color Quest XE (The Color Management Company, Reston, VA, USA) calibrated with a white and a black tile. Tests were repeated in triplicate for each treatment [24].

\subsection{Water Contact Angle}

The water contact angle was determined by drop shape analysis (DSA30E, Krüss Co. Ltd., Germany). The room temperature was set at $25.0 \pm 0.1{ }^{\circ} \mathrm{C}$. The water droplet with a volume of $10.0 \pm 0.5 \mu \mathrm{L}$ was dropped on a solid surface and images were taken every $6 \mathrm{~s}$ for $1 \mathrm{~min}$ [25].

\subsection{Oxygen Permeability}

The oxygen permeability $(O P)$ of the film was determined according to the ASTM D-3985 method using the OX-TRAN model@ 2/21 system (Minneapolis, USA) [26]. OP was determined using Equation (6):

$$
O P=\frac{O T R \cdot l}{\Delta P}
$$

Where $O P\left(\mathrm{cc} \cdot \mathrm{mm} / \mathrm{m}^{2}\right.$.day) and $O T R\left(\mathrm{cc} / \mathrm{m}^{2} \cdot\right.$ day $),(\Delta P)$ is the difference in oxygen partial pressure between the two sides of the film, and 1 is the thickness of the film.

\subsection{Fourier transform infrared (FTIR) spectroscopy}

P, NCS, and P/NCS films were characterized by Fourier transform (FTIR) spectrophotometer (Thermo Nicolet 6700, Waltham, MA, USA). The FTIR spectra were recorded in absorbance mode at a wavelength range of $500 \mathrm{~cm}^{-1}$ to $4000 \mathrm{~cm}^{-1}$ and with a resolution of $4 \mathrm{~cm}^{-1}$. 


\subsection{Scanning Electron Microscopy (SEM)}

The surface and cross section of the P, NCS, and P/NCS films were investigated by scanning electron microscopy (JEOL, JSM-5910LV, Tokyo, Japan). Cross-sectional samples were dipped in liquid nitrogen and then coated with gold under vacuum. The surface and cross-sectional morphologies of the film were recorded with over $1000 \times$ magnification [24].

\subsection{Antimicrobial Action of Film-Forming Solutions}

The antimicrobial activity of all film-forming solutions was tested against contaminating microorganisms typically found in food and fruit (Saccharomyces cerevisiae, Escherichia coli, Colletotrichum gloeosporioides, Aspergillus niger) using the agar well diffusion method. This method was described in detail by Ngo [21].

\subsection{Statistical Analysis}

Minitab 16 software (Version 16.2.3.0, Minitab Statistical Software, Bac Tu Liem, HN, Vietnam) was used to analyze the results in this study. Comparisons among multiple groups were evaluated by one-way analysis of variance (ANOVA).

\section{Conclusions}

In this work, the new films composed of pectin (P) and nanochitosan (NCS) were obtained. The blending of pectin with nanochitosan led to an improvement of mechanical properties, barrier properties, and hydration properties. Moisture sorption isotherms indicated the hydrophobic character of the P:NCS films, and the pectin:nanochitosan films, especially, inhibited the growth of S. cerevisiae, A. niger, C.gloeosporioides and E. coli. The ATR-FTIR spectra and SEM images for P:NCS 50:50 film indicated good interaction of film-forming components. These characterizations show that the pectin and nanochitosan films are a new approach for the development of active packaging for extending the shelf life of food products.

Author Contributions: Conceptualization, T.M.P.N.; Methodology, T.M.P.N. and T.H.N.; Validation, T.M.P.N., T.X.T., T.M.Q.D. and P.R.; Formal Analysis, T.M.P.N., T.X.T., T.M.Q.D. and P.R.; Investigation, T.M.P.N., T.X.T., T.M.Q.D. and P.R; Resources, T.M.P.N., T.X.T. and T.M.Q.D.; Writing-Original Draft Preparation, T.M.P.N.; Writing-Review and Editing, P.R.; Visualization, P.R.; Funding acquisition, P.R. and Supervision, P.R. All authors have read and agreed to the published version of the manuscript.

Funding: This research is funded by Funds for Science and Technology Development of the University of Danang under project number B2019-DN01-21-HT. The authors gratefully acknowledge the financial support from the Fund of Science and Technology Development of the University of Danang, Vietnam and Danang Department of Science and Technology, Vietnam. This research work was partially supported by Chiang Mai University.

Acknowledgments: We would like to thank the University of Technology and Education (UTE), University of Technology and Science (DUT), The University of Danang and Faculty of Agro-Industry, Chiang Mai University (CMU) for the equipment and facilities support. This research work was partially supported by Chiang Mai University.

Conflicts of Interest: The authors declare no conflict of interest. The funders had no role in the design of the study; in the collection, analyses, or interpretation of data; in the writing of the manuscript, or in the decision to publish the results.

\section{Abbreviations}

$\begin{array}{ll}\text { NCS } & \text { Nanochitosan } \\ \text { P } & \text { Pectin } \\ \text { SEM } & \text { Scanning electron microscope } \\ \text { FTIR } & \text { Fourier Transform infrared } \\ \text { MAA } & \text { Methacrylic acid } \\ \text { CS } & \text { Chitosan }\end{array}$




\section{References}

1. Hosseini, S.F.; Zandi, M.; Farahmandghavi, F. Development of bioactive fish gelatin/chitosan nanoparticles composite films with antimicrobial properties. Food Chem 2016, 194, 1266-1274. [CrossRef] [PubMed]

2. Espitia, P.J.P.; Du, W.X.; de Jesús Avena-Bustillos, R.; Soares, N.D.F.F.; McHugh, T.H. Edible films from pectin: Physical-mechanical and antimicrobial properties-A review. Food Hydrocoll. 2014, 35, 287-296. [CrossRef]

3. Maftoonazad, N.; Badii, F.; Shahamirian, M. Recent innovations in the area of edible films and coatings. Recent Pat. FoodNutr. Agric. 2013, 5, 201-213. [CrossRef] [PubMed]

4. Marcia, P.M.C.; Lourençode, M.F.; Mauricio, T.M.C. New polyelectrolyte complex from pectin/chitosan and montmorillonite clay. Carbohydr. Polym. 2016, 146, 123-130.

5. de Moura, M.R.; Luiz, F.A.A.; Mattoso, H.C. Preparation of chitosan nanoparticles using methacrylic acid. J. Colloid Interface Sci. 2008, 321, 477-483. [CrossRef]

6. Odegard, G.M.; Clancy, T.C.; Gates, T.S. Modeling of the mechanical properties of nanoparticle/polymer composites. Polymer 2005, 46, 553-562. [CrossRef]

7. Chang, P.R.; Jian, R.; Yu, J.; Ma, X. Preparation and properties of glycerol plasticized-starch (GPS)/cellulose nanoparticle (CN) composites. Carbohydr. Polym. 2010, 79, 301-305. [CrossRef]

8. Parris, N.C.D.R.; Joubran, R.F.; Pessen, H. Composition factors affecting the water vapor permeability and tensile properties of hydrophilic films. J. Agric. Food Chem. 1995, 43, 1432-1435. [CrossRef]

9. Divya, K.; Vijayan, S.; Tijith, K.G.; Jisha, M.S. Antimicrobial properties of chitosan nanoparticles: Mode of action and factors affecting activity. Fibers Polym. 2017, 18, 221-230. [CrossRef]

10. Sahraee, S.; Milani, J.M.; Ghanbarzadeh, B.; Hamishehkar, H. Physicochemical and antifungal properties of bio-nanocomposite film-based on gelatin-chitin nanoparticles. Int. J. Biol. Macromol. 2017, 97, 373-381. [CrossRef]

11. Verma, A.K. Anti-oxidant activities of biopolymeric nanoparticles: Boon or bane. J. Pharm. Res. 2014, 8, 871-876.

12. Rungsinee, S.; Pitak, N. Oxygen permeability and mechanical properties of banana films. Food Res. Int. 2007, 40, 365-370.

13. Woranuch, S.; Yoksan, R. Eugenol-loaded chitosan nanoparticles: I. Thermal stability improvement of eugenol through encapsulation. Carbohydr Polym 2013, 96, 78-85. [CrossRef] [PubMed]

14. Synytsya, A.; Čopíková, J.; Marounek, M.; Mlčochová, P.; Blafková, P.; Tkadlecová, M.; Havlíček, J. Preparation of N-alkylamides of highly methylated (HM) citrus pectin. Czech. J. Food Sci. 2003, 21, 162-166. [CrossRef]

15. Ngo, T.M.P.; Tran, T.X. Optimization of pectin extraction from yanang leaves and making pectin-alginate films. J. Sci. Technol. Univ. DanangVietnam. 2016, 11, 170-174.

16. Nguyen, T.M.N.; Nguyen, D.L.; Tran, T.M. Effect of nano chitosan on property of HPMC-Carnauba composite films and quality of the coated bananas. Vietnam J. Sci. Technol. 2016, 54, 105-114.

17. Nguyen, T.M.N.; Nguyen, T.T.Q.; Tran, T.M.; Nguyen, D.L. Synthesis of nano chitosan by using methacrylic acid and evaluation of antibacterial activity against Colletotrichum Musae associated with banana anthracnose. J. Sci. Technol. Vietnam Acad. Sci. Technol. 2015, 53, 8-14.

18. Gontard, N.; Guilbert, S.; Cuq, J. Edible wheat gluten films: Influence of the main process variables on film properties using response surface methodology. J. Food Sci. 1992, 57, 190-195. [CrossRef]

19. Kieckbusch, T.G.; da Silva, M.A. Natamycin release from alginate/pectin films for food packaging applications. J. Food Eng. 2012, 110, 18-25.

20. Rachtanapun, P.; Rattanapanone, N. Synthesis and characterization of carboxymethyl cellulose powder and films from Mimosa pigra. J. Appl. Polym. Sci. 2011, 122, 3218-3226. [CrossRef]

21. Ngo, T.M.P.; Dang, T.M.Q.; Tran, T.X.; Rachtanapun, P. Effects of zinc oxide nanoparticles on properties of pectin/alginate edible films. Int. J. Polym. Sci. 2018. [CrossRef]

22. Quyen, D.T.M.; Adisak, J.; Rachtanapun, P. Relationship between Solubility, Moisture Sorption Isotherms and Morphology of Chitosan/methylcellulose Films with Different Carbendazim Content. J. Agric. Sci. 2012, 4, 188-196. [CrossRef]

23. ASTM, Standard test methods for tensile properties of thin plastic sheeting D882-10. In Annual Book of ASTM; American Society for Testing and Materials: Philadelphia, PA, USA, 2010.

24. Galus, S.; Lenart, A. Development and characterization of composite edible films based on sodium alginate and pectin. J. Food Eng. 2013, 115, 459-465. [CrossRef] 
25. Jantanasakulwong, N.L.; Seesuriyachan, P.; Wongsuriyasak, S.; Techapun, C.; Ougizawa, T. Reactive blending of thermoplastic starch and polyethylene-graft-maleic anhydride with chitosan as compatibilizer. Carbohydr. Polym. 2016, 153, 89-95. [CrossRef]

26. ASTM D3985-05, Standard Test Method for Oxygen Gas Transmission Rate Through Plastic Film and Sheeting Using a Coulometric Sensor Book of Standards. Astm Int. 2010. Available online: https://standards.globalspec.com/std/10198811/ASTM\%20D3985 (accessed on 19 March 2020).

(C) 2020 by the authors. Licensee MDPI, Basel, Switzerland. This article is an open access article distributed under the terms and conditions of the Creative Commons Attribution (CC BY) license (http://creativecommons.org/licenses/by/4.0/). 